\title{
Sex-related differences in pharmacokinetics and pharmacodynamics of anti-hypertensive drugs
}

\author{
Koichi Ueno ${ }^{1,2}$ and Hiromi Sato ${ }^{1}$
}

Sex-specific differences in pharmacokinetics and pharmacodynamics have been reported to have important clinical consequences. In this review, some representative sex-specific differences in absorption and transporters (that is, P-glycoprotein (P-gp)), metabolic processes (that is, those that involve cytochrome P450 (CYP)), clearance ( $\mathrm{Cl}$ ) processes (for example, renal excretion or other pharmacokinetic parameters) and involvement of sex hormones (that is, estrogen and testosterone) in the regulation of some metabolic enzymes are introduced for each of the following categories of anti-hypertensive drugs: calciumchannel blockers, angiotensin-receptor blockers and angiotensin-converting enzyme inhibitors, diuretic agents, and $\beta$-adrenergicreceptor blockers ( $\beta$-blockers). In many cases, female sex is a risk factor for adverse effects or attenuated clinical responses because of lower $\mathrm{Cl}$, smaller distribution volumes, higher activity of some metabolic enzymes (especially hepatic CYP3A4), or presence of sex hormones. Additionally, some of these factors often co-contribute to the sex-specific differences. Furthermore, pharmacodynamic variability among individuals is often larger than pharmacokinetic variability; in other words, it could become a predominant determinant of interindividual differences in therapeutic responses. Thus, studies of sex-specific differences in pharmacokinetics and pharmacodynamics should be conducted. However, sex-related disparities in pharmacokinetics may not necessarily correspond to clinically significant differences in therapeutic response. There are still large gaps in our knowledge of sex-specific differences in clinical pharmacology and much more research is needed.

Hypertension Research (2012) 35, 245-250; doi:10.1038/hr.2011.189; published online 17 November 2011

Keywords: anti-hypertensive drug; pharmacodynamics; pharmacokinetics; sex differences

\section{INTRODUCTION}

Pharmacokinetics is a term that describes the kinetics of the processes undergone by drugs, food or other external agents in the body. It comprises main four steps: absorption, distribution, metabolism and clearance $(\mathrm{Cl})$ from the body. Extensive reviews of the pharmacokinetically important differences between the sexes have already been published. ${ }^{1-3}$ For example, Anderson has reported that men generally weigh more than women, yet few drugs are dosed on the basis of body weight. Drug concentrations are dependent on the volume of distribution and $\mathrm{Cl}$. Both parameters are dependent on body weight for most drugs independently of other sex-related differences. Women have a higher percent body fat than men, which can affect the volume of distribution of certain drugs. Renal $\mathrm{Cl}$ of unchanged drugs is decreased in women because of a lower rate of glomerular filtration. Sex-specific differences in activities of cytochrome P450 (CYP), transporters, uridine diphosphate glucuronosyltransferase enzymes, and renal excretion will result in differences in $\mathrm{Cl}$. There is evidence that women have lower activities of CYP1A2, CYP2E1, ${ }^{1}$ P-glycoprotein (P-gp) ${ }^{2}$ and uridine diphosphate glucuronosyltransferase, ${ }^{2}$ higher activities of CYP3A4, ${ }^{1,2} \mathrm{CYP}^{\mathrm{A}} 6^{2}$ and
CYP2B $6{ }^{2}$ and no differences in CYP2C $9^{1,2}$ and CYP2D6 ${ }^{2}$ activities. Additionally, pharmacodynamic factors (the relationship between drug concentration and the effects at each site of activity) are often involved in pharmacokinetics. In this review, we introduce some of the known sex-related differences in pharmacokinetic or pharmacodynamic processes for anti-hypertensive drugs in the following categories: (1) calcium-channel blockers; (2) agents that regulate the renin-angiotensin system, such as angiotensinreceptor blockers (ARBs) and angiotensin-converting enzyme (ACE) inhibitors; (3) diuretic agents; and (4) $\beta$-adrenergic-receptor blockers ( $\beta$-blockers).

\section{CALCIUM-CHANNEL BLOCKERS}

Non-dihydropyridine-type: verapamil

The calcium-channel blocker verapamil was one of the first wellcharacterized P-gp substrates. It is also a well-known substrate of CYP3A4 and undergoes extensive first-pass intestinal and hepatic metabolism. Verapamil is metabolized to norverapamil by CYP3A4. Dadashzadeh et al. ${ }^{4}$ reported that the ratios of the pharmacokinetic parameters of norverapamil to those of verapamil differed by sex in

${ }^{1}$ Department of Geriatric Pharmacology and Therapeutics, Graduate School of Pharmaceutical Sciences, Chiba University, Chiba, Japan and ${ }^{2}$ Center for Preventive Medical Science, Chiba University, Chiba, Japan

Correspondence: Dr K Ueno, Department of Geriatric Pharmacology and Therapeutics, Graduate School of Pharmaceutical Sciences, Chiba University, 1-8-1 Inohana, Chuo-ku, Chiba-shi, Chiba 260-8675, Japan.

E-mail: kueno@p.chiba-u.ac.jp

Received 1 June 2011; revised 16 September 2011; accepted 21 September 2011; published online 17 November 2011 
volunteers after administration of a single $80-\mathrm{mg}$ oral dose. The ratio of area under the blood concentration-time curve (AUC) at $0-24 \mathrm{~h}$ after administration and of AUC at $0-\infty \mathrm{h}$ after administration for norverapamil to that for verapamil were significantly higher in women than in men. There are two possible explanations: more extensive production of norverapamil or slower elimination of norverapamil in women compared with that in men. However, in their study, the mean residence time of norverapamil in women was significantly shorter than in men. Therefore, Dadashzadeh et al. ${ }^{4}$ concluded that norverapamil production is a sex-dependent process that is carried out more extensively in women than in men because of a higher activity of CYP3A4 or lower activity of P-gp.

The observation that $\mathrm{Cl}$ of drugs metabolized by CYP3A4 is frequently higher in women than in men is a classic example of a sex-related metabolic difference. The expression of both CYP3A4 protein and mRNA levels is higher in women than in men. ${ }^{5}$ Nevertheless, some studies that examined CYP3A4 protein content and function from the human liver were not able to show any significant sex-specific differences. ${ }^{6-9}$ Cummins et al. ${ }^{9}$ indicated that whether the sex-specific differences in $\mathrm{Cl}$ of a CYP3A4 substrate are apparent depends on P-gp activity; if a drug is metabolized by CYP3A4 and it is also a substrate of $\mathrm{P}$-gp, one might expect higher intracellular hepatic levels and consequently increased opportunities for the drug to encounter its metabolizing enzymes. This will result in greater metabolism and higher $\mathrm{Cl}$ rates, even though the enzyme protein levels are similar between men and women. On the other hand, if a drug is a substrate of CYP3A4 but not P-gp, intracellular drug concentration will not differ between men and women and no difference in $\mathrm{Cl}$ will be generated.

Another study reported that oral $\mathrm{Cl}$ of verapamil in men was faster than in women when administered in either a sustained-release or a regular-release formulation. ${ }^{10}$ These data are in contrast to those in previous reports of faster $\mathrm{Cl}$ of i.v.-administerd racemic verapamil, $\mathrm{R}$ verapamil and S-verapamil, and i.v.-administered erythromycin in women compared with men. ${ }^{11}$ Krecic-Shepard et al. ${ }^{10}$ explained that the reasons for these different results include individual variations, alternative pathways in the metabolism of CYP3A4 substrates, route of drug administration, and differences in competition for transport mechanisms. Thus, they suggested a need for investigation of not only pathway-specific probes but also multiple routes of administration and formulation when studying differences in human subgroups or for elucidating dosing guidelines in human beings.

\section{Dihydropyridine-type: amlodipine}

Amlodipine is a well-tolerated and widely used long-acting calciumchannel antagonist. It is metabolized by multiple CYP pathways including CYP3A4, which has low rates of first-pass metabolism and high bioavailability, and is not generally considered to be a P-gp substrate. Unlike most other calcium-channel blockers, it has been safely used in patients with New York Heart Association classes II and III heart failure. The efficacy and safety of amlodipine has been extensively assessed in several studies. Kloner et al. ${ }^{12}$ compared the response to amlodipine in men and women between 21 and 80 years of age, who had mild to moderate hypertension. The prospective, open-labeled, 18-week study (including four steps; wash out, titration, maintenance and long-term therapy) was conducted with 5-10 mg of amlodipine. The response of diastolic blood pressure (BP) to amlodipine therapy was greater in women $(91.4 \%)$ than in men $(83.0 \%$, $P \leqslant 0.001$ ), even after adjustment for baseline BP, age, weight and dose in milligrams per kilogram. ${ }^{12}$ Although the reason for the difference in response to the drug by sex was not known, the authors suggested such plausible explanations as vascular reactivity, distribution and metabolism of the drug, and differences in the pathology of hypertension between the sexes. They concluded that anti-hypertensive agents such as amlodipine might be used as probes to better understand these differences. Some other studies also suggested that even relatively small differences in BP can, in general, have prognostic significance. ${ }^{13,14}$ On the other hand, Kloner et al. ${ }^{12}$ also reported that women had a higher incidence of edema induced by treatment with amlodipine than did men, although, as previously stated, this was combined with a greater therapeutic response. They concluded that a higher relative dose may have explained the greater edema, but did not fully explain the sex-specific differences in $\mathrm{BP}$ response.

Another study examined the effects of age on the apparent oral $\mathrm{Cl}$ $(\mathrm{CL} / \mathrm{F})$ of amlodipine. ${ }^{15}$ Patients receiving stable doses of amlodipine for longer than 3 months were recruited for participation, and blood samples were collected. The average age was very old (men, 72 years; women, 79 years) because the authors enrolled elderly patients and residents of nursing homes. This cohort has rarely been included in investigations of medications. It comprises the oldest and frailest patients, includes more women than men, and is thought to have increased risks for adverse effects. Significant effects of sex were observed, with faster $\mathrm{CL} / \mathrm{F}$ in women compared with men. This result is similar to that for many other substrates of CYP3A4. These findings support the hypothesis that CYP3A4 expression is greater in liver tissues from women than from men. Furthermore, many in vivo studies of aging in healthy humans show a greater decrease in CYP3A4 in men compared with women. ${ }^{16}$ Kang et al. ${ }^{15}$ therefore, noted that findings from studies of physiologic aging excluding the very old, women, and minorities may not accurately reflect the $\mathrm{Cl}$ characteristics in older patients who are likely to receive medications.

\section{DRUGS REGULATING THE RENIN-ANGIOTENSIN SYSTEM (RAS)}

Sexual dimorphism of RAS

Men are at higher risk for cardiovascular disease and have increased incidence and severity of hypertension than women. Also, men generally exhibit greater renal injury and progress to end-stage renal failure at a more rapid rate than do women. RAS has been shown to have an important role in the control of BP. However, it has not yet been elucidated whether RAS has a role in the sexual dimorphisms of BP and renal injury. Some studies in animal models are instructive. ${ }^{17-}$ 19 They have shown that angiotensin II (Ang II) causes a greater increase in BP in normosensitive male rats and mice than in females ${ }^{17,18}$ and that sex-steroids could modulate the expression and activity of the various components of RAS in the kidney and other tissues. ${ }^{19}$ So, there might be sex-specific differences in the endogenous baseline RAS in normosensitive animals and humans that could alter the BP responses to Ang II or inhibitors of RAS. Sartori-Valinotti et al. ${ }^{20}$ revealed that the ACE inhibitor enalapril maintained the mean arterial pressures in female rats, whereas it could not do so in male rats when fed a high-salt diet. They speculated that Ang II might affect efferent arteriolar resistance more than afferent arteriolar resistance in female animals because of the estrogen-mediated increase in nitric oxide that would preferentially influence afferent resistance and lead to increased glomerular capillary pressure. Finally, there is a report that estrogen receptor alpha has a role in lowering BP in female animals, ${ }^{21}$ although this result is not borne out by other studies. Additional investigations are needed to determine the involvement of the estrogen receptor. 


\section{Angiotensin-receptor blockers}

ARBs are among the most useful drugs in Japan and, along with calcium-channel blockers, account for $70 \%$ of the medications used for treatment of hypertension. On the other hand, ACE inhibitors, calcium-channel blockers and $\beta$-blockers are often used in Western countries. The excellent effects of ARBs have been demonstrated in recent large-scale clinical trials, including the CASE-J, Jikei Heart and HIJ-CREATE studies. ${ }^{22}$ One ARB, candesartan cilexetil, which blocks the angiotensin II receptor, was discovered in Japan in 1982. By the end of 2009, five randomized prospective clinical trials had been conducted in Japan. From the analyses of the data obtained, candesartan-based treatment for hypertensive patients with or without other cardiovascular diseases was effective in the Japanese population, as well as in patients from Western countries. ${ }^{23}$ Dual therapy with irbesartan and hydrochlorothiazide, as well as combinations of other ARBs and diuretics, ACE inhibitors or $\beta$-blockers and diuretics, and ACE inhibitors and calcium-channel blockers have been shown to reduce $\mathrm{BP}$ in hypertensive patients. ${ }^{24} \mathrm{~A}$ secondary analysis of the data obtained by the Irbesartan/Hydrochlorothiazide Blood Pressure Reduction in Diverse Patients Populations (INCLUSIVE) study revealed that the decrease in systolic BP was significantly greater in women than in men $(P=0.002) .^{24}$ Although a previous study proposed that women might find it more difficult to lose weight and might possibly respond more favorably to dietary sodium reduction, whether women and men respond differently to anti-hypertensive therapy or require different anti-hypertensive therapy has been questioned. ${ }^{25}$ Studies with irbesartan/hydrochlorothiazide showed that there were no sex-specific differences in its pharmacokinetics observed in healthy adults or in its half-life or accumulation in hypertensive patients, although somewhat higher plasma concentrations of the ARB were observed in women than in men (11-44\%). ${ }^{26}$ Another study indicated that women had greater sensitivity to RAS blockade. ${ }^{27}$

In a study evaluating valsartan/hydrochlorothiazide combination therapy, the change in systolic BP was greater in the patients who received combination therapy than in those who received valsartan monotherapy for any comparison subgroup of sex, race or age. ${ }^{28}$ After controlling for baseline $\mathrm{BP}$ and randomized treatment assignment, the mean decrease in systolic BP at 6 weeks was $3.4 \mathrm{~mm} \mathrm{Hg}$ greater for women than men $(P<0.001)$, although the reason for the difference was not clear. ${ }^{28}$

\section{ACE inhibitors}

A bioequivalent clinical trial examining the effectiveness with a single 20-mg dose of two formulations of the ACE inhibitor enalapril in healthy male and female volunteers has been performed. ${ }^{29}$ The trial showed that the basal activity of ACE and its maximum inhibition were significantly lower in women, but no significant differences in the drug concentration required to produce $50 \%$ of Emax (the maximum ACE inhibition in percentage) were observed. Also, ACE inhibition was comparable between men and women when the plasma concentration exceeded $5 \mathrm{ng} \mathrm{ml}^{-1}$ at $20-24 \mathrm{~h}$ after dosing. From the perspective of the parallel with the differences in mean residence time and the volume of distribution throughout the menstrual cycle, the authors concluded that pharmacokinetic changes according to phase of menstrual cycle and hormonal status in women must be considered in the daily administration of enalapril to hypertensive patients and in the design of bioequivalent trials. On the other hand, there is also a report that men had a larger decrease in ambulatory blood pressure in response to lisinopril compared with women. ${ }^{30}$

Sullivan ${ }^{31}$ suggests that over time, the effectiveness of ACE inhibition is diminished in women, which is supported by additional cardiovascular studies in patients with congestive heart failure and after myocardial infarction in which ACE inhibition confers less cardiovascular benefit to women than to men. On the other hand, Pretorius et al. ${ }^{32}$ indicated that ACE inhibition by enalaprilat increases the release of basal tissue plasminogen activator, which has a potent cardioprotective effect through bradykinin stimulation, in both premenopausal and postmenopausal women more than in men. In their study, ACE activity after administration of enalaprilat was significantly decreased compared with baseline in all groups of premenopausal women, postmenopausal women, young men and older men, whereas there was no significant difference between premenopausal women and young men, or between postmenopausal women and older men. More studies are needed to specifically evaluate the effectiveness of ACE inhibition on chronic renal injury in women relative to men.

\section{DIURETIC AGENTS: TORASEMIDE}

Torasemide is frequently prescribed for the treatment of hypertension and heart failure because of its longer elimination half-life and a longer duration of action. Moreover, the determinants of torasemide pharmacokinetics in patients during steady-state conditions are largely unknown. Torasemide is cleared from the circulation mainly by hepatic metabolism and also by excretion into the urine. Werner et al. $^{33}$ examined the impact of genetic polymorphisms of CYP2C9, which is a primary enzyme in the metabolism of torasemide, and polymorphisms of liver-specific organic anion transporting peptide $1 \mathrm{~B} 1$ (SLCO1B1), as well as sex on the interindividual variability of the steady-state pharmacokinetics of torasemide. They showed that its dose-corrected maximum drug concentration $\left(C_{\max , s s}\right)$ was predicted only by female sex $(P=0.037)$, whereas the CYP2C9 genotype or heterozygosity for the SLCO1B1 c.521T > C SNP, which independently predicted the dose-adjusted area under the plasma concentration-time curve $\left(\mathrm{AUC}_{24, \mathrm{ss}}\right)$, had no significant effect on the torasemide $C_{\mathrm{max}, \mathrm{ss}}$. Both the $\mathrm{AUC}_{24, \mathrm{ss}}$ and $C_{\mathrm{max}, \mathrm{ss}}$ were about $40-50 \%$ higher in women than in men. In animal models, the effect of sex on the expression of proteins involved in the metabolism and excretion of torasemide has been described for the members of organic anion transporter family, which mediate the renal excretion of torasemide. ${ }^{34}$ Although sex-specific differences in the CYP2C9-dependent metabolism of drugs have not been frequently described, there is a report that no sex-specific difference in metabolism of CYP2C9 was seen. ${ }^{35}$ Werner et al. ${ }^{33}$ also refer to data from the German Pharmacovigilance Project showing that the majority of hospital admissions caused by adverse reactions to torasemide have occurred in women and indicated the need for reassessment of sex-specific differences in torasemide pharmacokinetics in future studies.

\section{$\beta$-BLOCKERS \\ $\beta_{1}$ Selective, intrinsic sympathomimetic activity negative: metoprolol}

There are several reports that women with hypertension appear to be less responsive to $\beta$-blockers than men. In a hypertension treatment study, the Hypertension Care Computing Project of the Department of Health and Social Security showed an improved survival in men with hypertension treated with $\beta$-blockers that was not seen among women. ${ }^{36}$ Similarly, decreases in coronary events and mortality or benefits for survival were seen only in men in the Medical Research Council Trial and in the $\beta$-Blocker Heart Attack Trial. ${ }^{37}$ Metoprolol is a $\beta$-blocking agent that is frequently used in the management of myocardial infarction, angina and hypertension. Luzier et al. ${ }^{38}$ examined whether there are sex-specific differences in the pharmacokinetics and pharmacodynamics of metoprolol enantiomers. Submaximal 
exercise was used to investigate heart rate and blood-pressure responses to metoprolol and to characterize the concentrationresponse relationship of $\beta$-blockade in male and female healthy volunteers. The results showed that sex-specific differences did in fact exist and that women had greater drug exposure (higher $C_{\max }$ and AUC) than men, although the concentration-effect relationships did not differ. Regarding pharmacodynamic parameters, the percentage reductions in heart rate and systolic BP from the drug-free phase were analyzed. Finally, it was demonstrated that the total area under the effect of curve for heart rate was significantly greater only in female volunteers. Beyond these findings, the authors suggested that the greater pharmacodynamic effect in women is a result of the higher plasma concentrations and greater drug exposure observed secondary to pharmacokinetic differences, and also that the greater exposure to metoprolol in women resulted in a more prolonged reduction in heart rate and greater area under the effect of curve. Therefore, women may require lower-than-standard doses to avoid adverse effects, whereas men may require larger doses to obtain therapeutic benefit. ${ }^{38}$

On the other hand, Cocco et al. ${ }^{39}$ reported a sex-specific difference in the ischemic effect of metoprolol, specifically that metoprolol showed a favorable effect in men but not in women in spite of a presumed higher plasma concentration of metoprolol in women. They demonstrated that the hemodynamic effects (reduction of blood pressure and heart rate) in men lead to a longer duration of exercise and increased time to angina, ST depression and total metabolic equivalents during exercise, which could reflect a better anti-ischemic effect in men. Cocco et al. ${ }^{39}$ indicated that we need to consider the sex-specific therapeutic effect of metoprolol and that it should be dosed according to the effect on the individual patient rather than according to fixed recommendations.

Metoprolol is known to be metabolized by CYP2D6. Approximately $85 \%$ of the administered dose of metoprolol is metabolized into three major metabolites ( $\alpha$-hydroxymetoprolol, $O$-desmethylmetoprolol and deaminated metoprolol), and among them, the metabolic pathway for $\alpha$-hydroxymetoprolol is exclusively mediated by CYP2D6. ${ }^{40}$ Therefore, it is possible that metoprolol could be affected by drugs that regulate CYP2D6. Diphenhydramine, a prototypic classic anti-histamine, competitively inhibits CYP2D6-mediated metoprolol $\alpha$-hydroxylation in human liver microsomes. ${ }^{41}$ In fact, some clinical studies revealed that the oral administration of diphenhydramine inhibited the partial metabolic conversion of metoprolol to $\alpha$-hydroxymetoprolol in healthy young men and women. ${ }^{42}$ Sharma et al. ${ }^{43}$ further investigated whether there were sex-specific differences in the pharmacokinetics and pharmacodynamics of metoprolol after the administration of a single oral 100-mg dose of metoprolol to extensive metabolizers (EMs) and poor metabolizers, and also whether there were sex-specific differences in the effect of the CYP2D6 inhibitor diphenhydramine on metoprolol disposition and hemodynamic effects. EM women had a significantly higher exposure to S-metoprolol compared with EM men because of significantly lower non-renal $\mathrm{Cl}$ capacities. As a result, EM women experienced a significantly greater reduction in heart rate than men. Furthermore, co-administration of diphenhydramine caused a greater reduction of non-renal $\mathrm{Cl}$ in $\mathrm{EM}$ women than in EM men. These results suggest that co-administration of metoprolol with a weak CYP2D6 inhibitor exposed EM women to a greater risk of pronounced and potentially adverse effects compared with EM men. Approximately $20-30 \%$ of clinically used drugs, endogenous neuroregulators and neurotoxins are CYP2D6 substrates. ${ }^{43}$ The metoprolol dose should be adjusted for body weight, particularly in women, and women should be particularly cautious when taking over-the-counter diphenhydramine in the higher dose range because it has a greater effect on metoprolol pharmacokinetics and pharmacodynamics.

\section{$\beta_{1}$ non-selective, intrinsic sympathomimetic activity negative: propranolol.}

Some investigations of sex-specific differences or the involvement of sex hormones in the metabolic $\mathrm{Cl}$ of propranolol have been reported. Xie et al. examined whether there are sex-specific differences in the pharmacokinetics of orally administered propranolol in healthy Chinese volunteers. The results showed that the AUC and Cmax of propranolol were higher in women than in men $(P<0.05)$, whereas the rate of oral $\mathrm{Cl}$ and apparent distribution volume were higher in men $(P<0.05) .{ }^{44}$ They concluded that the higher oral bioavailability (AUC and Cmax) of propranolol in Chinese women is in part caused by their lower rate of oral $\mathrm{Cl}$ and volume of distribution.

Another report focused on the metabolic pathways of propranolol. Walle et al. reported that higher plasma levels of this drug occurred in women than in men after oral doses. In this study, young white participants were administered a single $80-\mathrm{mg}$ oral dose of propranolol. The oral $\mathrm{Cl}$ rate was significantly higher in the men than in the women. The authors attributed this mainly to a higher rate of $\mathrm{Cl}$ through $\mathrm{P}-450$-mediated side-chain oxidation $(P<0.001)$ and glucuronidation $(P<0.02)$ in the men, whereas the $\mathrm{Cl}$ through $\mathrm{P}-450$ mediated ring oxidation was not different between men and women. ${ }^{45}$ Walle et al. ${ }^{46}$ also suggested the involvement of sex hormones in regulation of the activities of the sex-dependent pathways of propranolol metabolism in another report. After oral administration of propranolol, there was a positive correlation between the testosterone levels and the $\mathrm{Cl}$ of propranolol in young men through both alpha-naphtoxylactic acid $(P<0.001)$ and propranolol glucuronide $(P<0.002)$, as well as the total $\mathrm{Cl}(P<0.05)$. However, there was no significant association between the circulating levels of either estradiol or testosterone and the $\mathrm{Cl}$ of propranolol through any metabolite in women. These observations imply that sex and circulating gonadal hormones might influence propranolol metabolism and its clinical therapy.

\section{$\boldsymbol{\alpha}-\boldsymbol{\beta}$-Blocker: carvedilol}

Carvedilol is a useful drug for the treatment of hypertension with hyperlipidemia. Previously, a pharmacokinetic interaction between carvedilol and digoxin has been reported. Both are substrates of Pgp. Baris et al. ${ }^{47}$ evaluated the effect of sex on the influence of carvedilol on serum digoxin levels in patients with heart failure. After 1 week of administration, carvedilol caused a significant increase in the AUC and peak concentration of digoxin in the men but had no significant effect in the women. Carvedilol is metabolized by CYP2D6 and CYP2C9. ${ }^{48,49}$ It has been demonstrated that women of fertile age have slightly higher CYP2D6 activity compared with men. CYP2C9 activity does not seem to be sex-dependent, ${ }^{35}$ at least not to a clinically significant extent. In Baris et al.'s study, the combination of carvedilol and digoxin did not affect any pharmacokinetic parameters in women. On the other hand, the potential role of carvedilol in inhibiting the renal tubular secretion of digoxin was studied by Takara et al. ${ }^{50}$ Additionally, Aiba et al. ${ }^{49}$ demonstrated that carvedilol inhibits the transporters and suppresses digoxin efflux in the apical membrane. Generally, men seem to have a higher P-gp activity than women. ${ }^{48}$ Thus, P-gp inhibition by carvedilol might increase the absorption of digoxin (by inhibiting its efflux) and decrease the renal secretion of digoxin (by inhibiting efflux into the urine) in men. When the coadministration of these drugs is considered, serum digoxin levels should be monitored. 


\section{CONCLUSION}

Clear evidence for sex-specific differences in the pharmacokinetic or pharmacodynamic properties of anti-hypertension drugs has accumulated. The population most frequently in need of clinical treatment for hypertension or heart failure is, of course, the elderly. They often take many kinds of medications, so whole-body pharmacokinetics and pharmacodynamics must always be taken into consideration during treatment planning. Moreover, more than half of elderly individuals are women. Therefore, how women react to drugs is an important issue for which the available data are still unsatisfactory. To date, sexspecific differences have been identified for numerous molecular and physiologic factors that affect the pharmacokinetics of therapeutic drugs, and more differences may yet be elucidated by ongoing and future studies. However, clinically significant differences in therapeutic response resulting from sex-specific disparities in pharmacokinetics seem to be rare. Additionally, most of the accumulated data are from the USA or Western countries, with a few reports from Asian countries such as Iran, ${ }^{4}$ China ${ }^{44}$ and Turkey ${ }^{47}$ so it was difficult to discuss the involvement of ethnic and racial differences in this review. It is important to understand the current findings about such sex-specific responses and objectively apply this knowledge to clinical therapy. It is also important to take into account body weight and age, as well as co-morbidity in determining the appropriate drug regimen for both men and women.

\section{CONFLICT OF INTEREST}

The authors declare no conflict of interest.

\section{ACKNOWLEDGEMENTS}

We appreciate the assistance of Ms Momoko Ishikawa, Ms Tomomi Sato, Ms Asami Funaki, and Ms Miaki Uzu in literature searches. This study was partly supported by a Grant-in-Aid for Scientific Research (C) from the Japan Society for the Promotion of Sciences, and by a Health Labour Sciences Research Grant.

1 Anderson GD. Gender differences in pharmacological response. Int Rev Neurobiol 2008; 83: 1-10.

2 Schwartz JB. Drug metabolism. In Legato MJ (eds) Principles of Gender-Specific Medicine 2nd edn, Elsevier Academic Press: San Diego 2004, pp 825-829.

3 Anthony M, Berg MJ. Biologic and molecular mechanisms for sex differences in pharmacokinetics, pharmacodynamics, and pharmacogenetics: Part I. Workshop held at the National Institute of Health, May 4-6, 1999. J Womens Health Gend Based Med 2002; 11: 601-615.

4 Dadashzadeh S, Javadian B, Sadeghian S. The effect of gender on the pharmacokinetics of verapamil and norverapamil in human. Biopharm Drug Dispos 2006; 27: 329-334.

5 Wolbold R, Klein K, Burk O, Nüssler AK, Neuhaus P, Eichelbaum M, Schwab M, Zanger UM. Sex is a major determinant of CYP3A4 expression in human liver. Hepatology 2003; 38: 978-988.

6 George J, Byth K, Farrell GC. Age but not gender selectively affects expression of individual cytochrome P450 proteins in human liver. Biochem Pharmacol 1995; 50: 727-730.

7 Schmucker DL, Woodhouse KW, Wang RK, Wynne H, James OF, McManus M, Kremers $P$. Effects of age and gender on in vitro properties of human liver microsomal monooxygenases. Clin Pharmacol Ther 1990; 48: 365-374.

8 Shimada T, Yamazaki H, Mimura M, Inui Y, Guengerich FP. Interindividual variations in human liver cytochrome P-450 enzymes involved in the oxidation of drugs, carcinogens and toxic chemicals: studies with liver microsomes of 30 Japanese and 30 Caucasians. J Pharmacol Exp Ther 1994; 270: 414-423.

9 Cummins CL, Wu C-Y, Benet LZ. Sex-related differences in the clearance of cytochrome P450 3A4 substrates may be caused by P-glycoprotein. Clin Pharmacol Ther 2002; 72 : 474-489.

10 Krecic-Shepard ME, Barnas CR, Slimko J, Schwartz JB. Faster clearance of sustained release verapamil in men versus women: continuing observations on sex-specific differences after oral administration of verapamil. Clin Pharmacol Ther 2000; 68: 286-292.
11 Krecic-Shepard ME, Barnas CR, Slimko J, Groski J, Wainerl, Schwartz JB. In vivo comparison of putative probes of CYP3A4/5 activity: erythromycin, dextromethorphan, and verapamil. Clin Pharmacol Ther 1999; 66: 40-50.

12 Kloner RA, Sowers JR, DiBona GF, Gaffney M, Wein M. and age-related antihypertensive effects of amlodipine. The Amlodipine Cardiovascular Community Trial Study Group. Am J Cardiol 1996; 77: 713-722.

13 de Bruijn B, Cocco G, Tyler HM. Multicenter placebo-controlled comparison of amlodipine and atenolol in mild to moderate hypertension. $J$ Cardiovasc Pharmacol 1988; 12 (Suppl 7): S107-S109.

14 Lorimer AR, Smedsrud T, Walker P, Tyler HM. Comparison of amlodipine and verapamil in the treatment of mild to moderate hypertension. J Cardiovasc Pharmacol 1988; 12 (Suppl 7): S89-S93.

15 Kang D, Verotta D, Schwartz JB. Population analyses of amlodipine in patients living in the community and patients living in nursing homes. Clin Pharmacol Ther 2006; 79: $114-124$

16 Greenblatt DJ, Harmatz JS, von Moltke LL, Wright CE, Shader RI. Age and gender effects on the pharmacokinetics and pharmacodynamics of triazolam, a cytochrome P450 3A substrate. Clin Pharmacol Ther 2004; 76: 467-479.

17 Tatchum-Talom R, Eyster KM, Martin DS. Sexual dimorphism in angiotensin II-induced hypertension and vascular alterations. Can J Physiol Pharmacol 2005; 83: 413-422.

18 Xue B, Pamidimukkala J, Hay M. Sex differences in the development of angiotensin IIinduced hypertension in conscious mice. Am J Physiol Heart Circ Physiol 2005; 288: $\mathrm{H} 2177-\mathrm{H} 2184$.

19 Ellison KE, Ingelfinger JR, Pivor M, Dzau VJ. Androgen regulation of rat renal angiotensinogen messenger RNA expression. J Clin Invest 1989; 83: 1941-1945.

20 Sartori-Valinotti JC, Iliescu R, Yanes LL, Dorsett-Martin W, Reckelhoff JF. Sex differences in the pressor response to angiotensin II when the endogenous renin-angiotensin system is blocked. Hypertension 2008; 51: 1170-1176.

21 Xue B, Pamidimukkala J, Lubahn DB, Hay M. Estrogen receptor-alpha mediates estrogen protection from angiotensin II-induce hypertension in conscious female mice. Am J Physiol Heart Circ Physiol 2007; 292: H1770-H1776.

22 Saruta T. The contribution of ARB to medical treatment. Nippon Rinsho 2009; 67: 662-667.

23 Suzuki H, Araki R. Cardiovascular outcome of an angiotensin II receptor blocker, candesartan, in Japan. Drugs Today (Barc) 2010; 46: 427-431.

24 Saunders E, Cable G, Neutel J. Predictors of blood pressure response to angiotensin receptor blocker/diuretic combination therapy: a secondary analysis of the irbesartan/ hydrochlorothiazide blood pressure reductions in diverse patient populations (INCLUSIVE) study. J Clin Hypertens (Greenwich) 2008; 10: 27-33.

25 McBride SM, Flynn FW, Ren J. Cardiovascular alteration and treatment of hypertension: do men and women differ? Endocrine 2005; 28: 199-207.

26 Bristol-Myers Squibb. AVAPRO and AVALIDE: Hypertension treatment. Full Prescribing Information for AVALIDE ${ }^{\circledR}$ (irbesartan-hydrochlorothiazide). http://packageinserts.bms. com/pi/pi_avalide.pdf (accessed 2 May 2011)

27 Miller JA, Cherney DZ, Duncan JA, Lai V, Burns KD, Kennedy CR, Zimpelmann J, Gao W, Cattran DC, Scholey JW. Gender differences in the renal response to reninangiotensin system blockade. J Am Soc Nephrol 2006; 17: 2554-2560.

28 Everett BM, Glynn RJ, Danielson E, Ridker PM. Combination therapy versus monotherapy as initial treatment for stage 2 hypertension: a prespecified subgroup analysis of a community-based, randomized, open-label trial. Clin Ther 2008; 30: 661-672.

29 Zapater P, Novalbos J, Gallego-Sandín S, Hernández FT, Abad-Santos F. Gender differences in angiotensin-converting enzyme (ACE) activity and inhibition by enalaprilat in healthy volunteers. J Cardiovasc Pharmacol 2004; 43: 737-744.

30 Iconnet C, Bochud M, Bovet P, Maillard M, Burnier M. Gender difference in the response to an angiotensin-converting enzyme inhibitor and a diuretic in hypertensive patients of African descent. J Hypertens 2004; 22: 1213-1220.

31 Sullivan JC. Sex and the renin-angiotensin system: inequality between the sexes in response to RAS stimulation and inhibition. Am J Physiol Regul Integr Comp Physiol 2008; 294: R1220-R1226.

32 Pretorius M, Luther JM, Murphey LJ, Vaughan DE, Brown NJ. Angiotensin-converting enzyme inhibition increases basal vascular tissue plasminogen activator release in women but not in men. Arterioscler Thromb Vasc Biol 2005; 25: 2435-2440.

33 Werner D, Werner U, Meybaum A, Schmidt B, Umbreen S, Grosch A, Lestin HG, Graf B, Zolk O, Fromm MF. Determinants of steady-state torasemide pharmacokinetics: impact of pharmacogenetic factors, gender and angiotensin II receptor blockers. Clin Pharmacokinet 2008; 47: 323-332.

34 Cerrutti JA, Quaglia NB, Brandoni A, Torres AM. Effects of gender on the pharmacokinetics of drugs secreted by the renal organic anions transport systems in the rat. Pharmacol Res 2002; 45: 107-112.

35 Schwartz JB. The influence of sex on pharmacokinetics. Clin Pharmacokinet 2003; 42 : 107-121.

36 Fletcher A, Beevers DG, Bulpitt C, Butler A, Coles EC, Hunt D, Munro-Faure AD, Newson RB, O'Riordan PW, Petrie JC. Beta adrenoceptor blockade is associated with increased survival in male but not female hypertensive patients: a report from the DHSS Hypertension Care Computing Project (DHCCP). J Hum Hypertens 1988; 2: 219-227.

$37 \beta$-Blocker Heart Attack Trial Research Group. A randomized trial of propranolol in patients with acute myocardial infarction. I. Mortality results. JAMA 1982; 247: 1707-1714.

38 Luzier AB, Killian A, Wilton JH, Wilson MF, Forrest A, Kazierad DJ. Gender-related effects on metoprolol pharmacokinetics and pharmacodynamics in healthy volunteers. Clin Pharmacol Ther 1999; 66: 594-601. 
39 Cocco G, Chu D. The anti-ischemic effect of metoprolol in patients with chronic angina pectoris is gender-specific. Cardiology 2006; 106: 147-153.

40 Lennard MS, Tucker GT, Silas JH, Freestone S, Ramsay LE, Woods HF. Differential stereoselective metabolism of metoprolol in extensive and poor debrisoquin metabolizers. Clin Pharmacol Ther 1983; 34: 732-737.

41 Hamelin BA, Bouayad A, Méthot J, Jobin J, Desgagnés P, Poirier P, Allaire J, Dumesnil J, Turgeon J. Significant interaction between the nonprescription antihistamine diphenhydramine and the CYP2D6 substrate metoprolol in healthy men with high or low CYP2D6 activity. Clin Pharmacol Ther 2000; 67: 466-477.

42 Sharma A, Pibarot P, Pilote S, Dumesnil JG, Arsenault M, Bélanger PM, Meibohm B, Hamelin BA. Modulation of metoprolol pharmacokinetics and hemodynamics by diphenhydramine coadministration during exercise testing in healthy premenopausal women. J Pharmacol Exp Ther 2005; 313: 1172-1181.

43 Sharma A, Pibarot P, Pilote S, Dumesnil JG, Arsenault M, Bélanger PM, Meibohm B, Hamelin BA. Toward optimal treatment in women: the effect of sex on metoprololdiphenhydramine interaction. J Clin Pharmacol 2010; 50: 214-225.

$44 \mathrm{Xie} H \mathrm{HG}$, Chen X. Sex differences in pharmacokinetics of oral propranolol in healthy Chinese volunteers. Zhongguo Yao Li Xue Bao 1995; 16: 468-470.
45 Walle T, Walle UK, Cowart TD, Conradi EC. Pathway-selective sex differences in the metabolic clearance of propranolol in human subjects. Clin Pharmacol Ther 1989; 46: 257-263.

46 Walle T, Walle K, Mathur RS, Palesch YY, Conradi EC. Propranolol metabolism in normal subjects: association with sex steroid hormones. Clin Pharmacol Ther 1994; 56: 127-132.

47 Baris N, Kalkan S, Güneri S, Bozdemir V, Guven H. Influence of carvedilol on serum digoxin levels in heart failure: is there any gender difference? Eur J Clin Pharmacol 2006; 62: 535-538.

48 Meibohm B, Beierle I, Derendorf H. How important are gender differences in pharmacokinetics? Clin Pharmacokinet 2002; 41: 329-342.

49 Aiba T, Ishida K, Yoshinaga M, Okuno M, Hashimoto Y. Pharmacokinetic characterization of transcellular transport and drug interaction of digoxin in Caco-2 cell monolayers. Biol Pharm Bull 2005; 28: 114-119.

50 Takara K, Kakumoto M, Tanigawara Y, Funakoshi J, Sakaeda T, Okumura K. Interaction of digoxin with antihypertensive drugs via MDR1. Life Sci 2002; 70: 1491-1500. 